\title{
The Reality of Pixantrone in Real Life
}

\author{
Pierantonio Menna ${ }^{a}$ Emanuela Salvatorelli ${ }^{b}$ Giorgio Minotti ${ }^{a, b}$ \\ ${ }^{a}$ Clinical Pharmacology, University Campus Bio-Medico, Rome, Italy; ${ }^{b}$ Department of Medicine, University Campus \\ Bio-Medico, Rome, Italy
}

Relapsed/refractory (R/R) diffuse large B-cell lympho$\mathrm{ma}$ (DLBCL) is a challenging and poor-prognosis clinical setting. Many chemotherapeutics are used to treat the disease, and few innovative candidates are finding their way to consideration by regulatory agencies, but only one drug, pixantrone $\left(\right.$ Pixuvri $\left.^{\circledR}\right)$, has been formally approved by the European Medicines Agency (EMA) for use in patients with R/R DLBCL.

The popularity of pixantrone is nonetheless small, and the number of patients treated with pixantrone is not as high as one would expect for the only shining star in a dark sky. Some established facts can help to explain this counterintuitive situation. Pixantrone is an old-fashioned cytotoxic that struggles to find its niche in the era of molecularly targeted agents. The clinical development of pixantrone was long and rambling, with the trials leading to its conditional approval and standard marketing authorization (PIX 301 and PIX 306, respectively) showing some chiaroscuro results. The mechanism(s) of action of pixantrone remain(s) under scrutiny, and the once believed anthracycline-like mode of tumor cell killing probably does not recapitulate the efficacy of pixantrone in patients with $\mathrm{R} / \mathrm{R}$ DLBCL. In sum, too many consider pixantrone as a newly approved old drug, an oxymoron that rests with the less than optimally deciphered molecular and clinical characteristics of pixantrone.

$\begin{aligned} & \text { karger@karger.com } \\ & \text { www.karger.com/aha }\end{aligned}$
Karger $\%$

That being said, only real-life studies can help the hematologist to appreciate the therapeutic options offered by pixantrone. In this issue, Zinzani et al. [1] report on the efficacy and safety of pixantrone in patients with $\mathrm{R} / \mathrm{R}$ DLBCL. This report focuses on the Italian subset of $R / R$ DLBCL patients recruited in a retrospective observational European study (PIXA Registry) [2]. It is a minor piece of work, showing data from 15 patients only. The data are nonetheless encouraging enough to deserve attention and dissemination by word of mouth. All patients were heavily pretreated, some of them carrying the molecular signatures of double-hit and triple-hit DLBCL. The clinical setting was therefore unfavorable, letting the readers anticipate anything but a response to and tolerability of pixantrone; yet, the overall response rate was $26.7 \%$ (with a best response rate of $46.7 \%$ ), and some responses were of a noticeable duration. Only 3 patients developed grade IV toxicity causing treatment discontinuation, the grade III toxicities were consistent with the known characteristics of pixantrone, and only 1 case of mild cardiotoxicity was reported [2].

Not much else can be said at this point in time, since the sample size was too limited to permit open speculation. Nonetheless, the data are in fact a miniaturized example of what pixantrone can offer in the setting of $\mathrm{R} / \mathrm{R}$ DLBCL. Some considerations of precisely how the data 
were collected and archived in the registry should nonetheless be made. Many details could not be provided by the authors, which denotes an insufficient structuring of the registry. This is a missed opportunity, especially when the complexity of R/R DLBCL patients (frontline exposure to anthracycline, sequential lines of treatment, ineligibility to stem cell transplantation, high risk of failure and toxicity in salvage therapies) is weighed against the apparent efficacy and tolerability of pixantrone. Registries should definitely provide more and better-structured information.

Having dealt with the pros and cons of this report, the time is ripe to say a few words on the mechanisms of action of pixantrone in R/R DLBCL. Pixantrone is a lastgeneration anthracenedione, obtained by extensive chemical modification of mitoxantrone. As such, pixantrone has long been grouped with anthracycline-like drugs, but the very fact that it shows efficacy in anthracycline-pretreated patients casts doubt on whether pixantrone causes canonical anthracycline-like inhibition of topoisomerase IIa. Likewise, the cardiac tolerability of pixantrone in anthracycline-pretreated patients shows compelling evidence against pixantrone causing anthracycline-like cardiotoxicity or precipitating subclinical cardiotoxicity induced by prior anthracycline treatment. These are facts the hematologist should be aware of. The available preclinical evidence shows that pixantrone is in fact a relatively modest topoisomerase II $\alpha$ inhibitor but probably acts by inducing chromosome missegregation, waves of aberrant mitosis, and eventually mitotic catastrophe [3]. On the other hand, the established mechanisms of anthracycline cardiotoxicity, such as oxidative stress and/or formation of long-lived toxic metabolites, do not seem to operate when pixantrone is probed in translational models of the human heart sequentially exposed to anthracycline and pixantrone [4]. Thus, pixantrone is not an "old-looking new drug." Pixantrone is a new drug with new mechanisms of action in tumor cells and in the vulnerable heart [5].

The report by Zinzani et al. [1] - though markedly limited in sample size and missing corollary but important information - serves as one more piece of evidence of the pharmacodynamic and therapeutic value of pixantrone. Needless to say, much larger real-life studies are needed to successfully position pixantrone in the contemporary armamentarium against R/R DLBCL. We hope to see these studies soon.

\section{Conflict of Interest Statement}

The authors have no conflict of interest to declare.

\section{Funding Sources}

G.M. received research funds and consultancy honoraria from Cell Therapeutics Inc. (Seattle, WA, USA) and Servier Italy. No funding is currently provided by either company, and no funding was provided for the preparation of this commentary.

\section{Author Contributions}

All authors worked on the concept of the commentary. P.M. and G.M. wrote the commentary. All authors jointly revised and approved the commentary.

\section{References}

1 Zinzani PL, Bregni M, Spione M, Mitterer M, Musuraca G, Bugli A, et al. Effectiveness and safety of pixantrone for the treatment of relapsed or refractory diffuse large B-cell lymphoma in every day clinical practice: the Italian cohort of the PIXA Registry. Acta Haematol. DOI: $10.1159 / 000509923$.

2 Sancho JM, Navarro B, Soler Campos JA, de Oteyza JP, de Barrenetxea Lekue C, Bregni $\mathrm{M}$, et al. Efficacy and safety of pixantrone for the treatment of multiply relapsed or refractory aggressive non-Hodgkin B-cell lymphomas. Eur J Haematol. 2020 May;104(5): 499-508.

3 Menna P, Salvatorelli E, Minotti G. Rethinking drugs from chemistry to therapeutic opportunities: pixantrone beyond anthracyclines. Chem Res Toxicol. 2016 Aug;29(8):1270-8.

4 Salvatorelli E, Menna P, Paz OG, Chello M, Covino E, Singer JW, et al. The novel anthra- cenedione, pixantrone, lacks redox activity and inhibits doxorubicinol formation in human myocardium: insight to explain the cardiac safety of pixantrone in doxorubicintreated patients. J Pharmacol Exp Ther. 2013 Feb;344(2):467-78.

5 Minotti G, Han H, Cattan V, Egorov A, Bertoni F. Pixantrone: novel mode of action and clinical readouts. Expert Rev Hematol. 2018 Jul;11(7):587-96. 